\title{
Takayasu's arteritis: a rare disease in Poland
}

\author{
Krzysztof Kanecki ${ }^{1, A, C-F}$, Aneta Nitsch-Osuch, $1, A, C, E-F$, Piotr Zbigniew Tyszko, ${ }^{2, A, C, E-F}$, \\ Paweł Goryński ${ }^{3, A-C, E-F}$, Roman Smolarczyk ${ }^{4, A, C, E-F}$, Katarzyna Suchta ${ }^{4, A, C, E-F}$ \\ ${ }^{1}$ Department of Social Medicine and Public Health, Medical University, Warsaw, Poland \\ ${ }^{2}$ Institute of Rural Health, Lublin, Poland \\ ${ }^{3}$ National Institute of Public Health - National Institute of Hygiene, Warsaw, Poland \\ ${ }^{4}$ Department of Gynecological Endocrinology, Clinical Hospital of Duchess Anna Mazowiecka, Medical University, \\ Warsaw, Poland \\ A - Research concept and design, B - Collection and/or assembly of data, C - Data analysis and interpretation, \\ $D$ - Writing the article, E - Critical revision of the article, F - Final approval of article
}

Kanecki K, Nitsch-Osuch A, Tyszko PZ, Goryński P, Smolarczyk R, Suchta K. Takayasu's arteritis: a rare disease in Poland. Ann Agric Environ Med. 2018; 25(3): 469-472. doi: 10.26444/aaem/92702

\begin{abstract}
Introduction. Takayasu's arteritis (TA) is a rare and potentially life-threatening granulomatous large-vessel vasculitis that involves mostly in the aorta and its proximal branches, and occurs most commonly in young females. This study measures the incidence and prevalence of TA, and assesses the gender distribution and territorial differences in the occurrences of this disease in Poland over a five-year period. To the best of our knowledge, this is the first evaluation of this rare disease in Poland based on a hospital morbidity database.

Materials and method. Analyses were performed with population-based administrative data obtained from a national hospital morbidity study carried out between January 2011 - December 2015 by the Polish National Institute of Public Health. Yearly incidence rates and prevalence of TA were calculated using the number of TA patients and corresponding census data for the overall Polish population.

Results. Data included 660 hospitalization records. The final study sample comprised 177 patients: 154 female (87\%) and 23 male (13\%) with first-time hospitalization for TA. The mean age was 45.4years (95\% Cl: 42.9-47.8; SD 16.8; range 4-81 years), median 47. The incidence rate of TA was estimated at 0.92 per million per year ( $95 \% \mathrm{Cl}: 0.68-1.16)$. Five-year TA prevalence was estimated to be 4,6 per million. Incidence rates of TA did not vary significantly between more urban and more rural regions.

Conclusions. The incidence of TA in Poland was similar or lower to data reported by other European countries. The study provides epidemiological data on TA in Poland that may be useful while comparing it with other geographical regions.
\end{abstract}

\section{Key words}

vasculitis, epidemiology, aortoarteritis, pulseless disease, granulomatous arteritis, rural regions, urban regions

\section{INTRODUCTION}

Takayasu's arteritis (TA), a potentially life-threatening, granulomatous large vessel vasculitis involves mostly the aorta and its proximal branches, and occurs most commonly in young females. The data on the epidemiology of TA is limited, probably due to the rarity of the disease. Although the disease has a worldwide distribution, it is generally thought to be much more common among Asian populations. The true incidence and prevalence of TA is underestimated, and many patients remain undiagnosed or wait for a long time before the correct diagnosis is made [1-2]. In a recent study from Japan it was reported that the time from onset to diagnosis was significantly shortened in the past decade, which may be related to the development of noninvasive diagnostic imaging tools [3]. Pregnancy seems to cause serious risks for both maternal and foetal health. Epidemiological studies on TA are necessary as it was reported that there was a high prevalence of pregnancy-related concerns in TA patients, although the maternal and foetal outcomes were favourable [4]. TA negatively affects pregnancy outcomes and disease activity increases the risk of obstetric and maternal complications [5].

Address for correspondence: Katarzyna Suchta, Department of Gynecological Endocrinology, Karowa 2, 00-315 Warsaw, Poland

e-mail: suchta.katarzyna@onet.pl

Received: 08.04.2018; accepted: 29.06.2018; first published: 24.09.2018
The etiology of TA remains poorly understood, but genetic contribution to the disease pathogenesis is supported by the genetic association with HLA-B ${ }^{\star 52}[6-7]$. Genetic predisposition may be responsible for an increased occurrence of TA; however, there are differences in incidence and prevalence of this disease in different parts of the world. According to a nationwide Japanese registry, there were at least 5,881 patients with TA in Japan in 2012, with the prevalence believed to be over 40 per million [8]. In another study in Japan, the incidences of TA were estimated to be 1-2 per million [9]. In Turkey the situation was different region-dependent. In a hospital-based study conducted in the north-western part of Turkey (Eastern Thrace) the incidence was estimated to be 3.4 per million per year [10]. In other Turkish study the annual prevalence was estimated as 12.8 (95\% CI 12.0-13.6) per million; 23.5/million (95\% CI 21.9-25.0) in females and 1.9/million (95\% CI 1.5-2.4) in males. The prevalence was higher at $8.8 /$ million $(95 \%$ CI $7.7-10.0$ ) in the population $>40$ years of age. During the study period, the mean annual incidence of TA was estimated as $1.11 /$ million (95\% CI 0.54-1.67) [11]. In Israel, the incidence of Takayasu's arteritis was reported to be 2.1 per million (95\% CI 1.2-2.9) [12]. In Western Australia, per million inhabitants the annual incidence and prevalence was 0.3 and 3.2 for Caucasians and 1.1 and 15 for Asians [13]. In Arabs, the demographical and clinical findings of TA were reported to be similar to that reported from different parts of the world [14]. 
TA is regarded as an endemic disease among Asian populations. However, recently studies from Europe show an increasing tendency of incidence and prevalence of this rare disease in the Old Continent although the studies on the incidence of TA are rather limited. A study conducted in Germany (Federal State of Schleswig-Holstein, north Germany) that covered the period 1998-2002 indicates the incidence of Takayasu's arteritis to be $0.4-1.0$ per million per year [15], based on data from the Regional Registry that covered mainly hospital records. Similar incidence can be observed in the United Kingdom (Norfolk county, eastern England) in a study that covered the period 2000-2005. It indicates the incidence of Takayasu's arteritis to be 0.8 per million per year overall, and about 0.3 per million per year when only patients below 40 years of age were take into consideration [16]. A Swedish (Skåne) hospital-based study for the period 1997-2011 estimated the incidence of TA to be about 0.7 per million per year [17]. Meanwhile, a Danish study that covered the period 1990-2009 in the eastern part of the country, based on the Central Registry (1990-2006) and hospital-based data (20072009), estimated the incidence of TA to be about 0.4 per million per year overall, and about 0.6 per million per year when the patients under 40 years were taken into consideration [18]. Contrary to these incidences, three other European countriessouth-east Norway [19], Spain [20] and Lithuania [21], are situated where the incidences of TA is estimated at between 1-2 per million. Among Scandinavian countries, the prevalence of Takayasu's arteritis is highest in Norway and calculated to be between 22-25 per million [19]. In contrast, in Sweden the prevalence is twice as low and estimated to be 13.2 per million [17]. The prevalence in Spain in hospital-based study is estimated to be 10,5 per million [20]. The lowest prevalence in Europe is estimated in the United Kingdom - 4.7 per million [16]. In Denmark, in a study based on Central Registry and hospital data, the prevalence of Takayasu's arteritis is calculated to be 8 per million overall, and about 12 per million when patients $<40$ years are considered [18].

\section{OBJECTIVES}

Apart from case reports, there is little information regarding TA in Poland [22-28]. The presented study measured the incidence and prevalence of TA, and assessed its gender distribution and territorial differences in Poland over a fiveyear period. To the best of our knowledge, this is the first evaluation of this rare disease in Poland based on a hospital morbidity database.

\section{MATERIALS AND METHOD}

This is a population-based and retrospective study using hospital discharge records with Takayasu's arteritis diagnosis obtained from a Polish National Institute of Public Health survey. The data originates from the period 2011-2015. The study evaluated records on all first-time hospitalized patients with Takayasu's disease diagnosis. This data are obligatory sent to the National Institute of Public Health from all hospitals, with the exceptions of psychiatric and military hospitals. These anonymous records consist of information on ICD10 diagnosis, date of admittance, date of discharge, date of birth, gender, and place of residence.
In a Turkish study, a case search was performed electronically in the information systems of these hospitals using The International Classification of Diseases Tenth Revision (ICD-10) code for Takayasu's arteritis (M31.4) [11]. In the current study, two analytic samples were taken into consideration - all hospitalizations for Takayasu's arteritis and first-time hospitalizations for Takayasu's arteritis. Beside data from the hospital morbidity study, demographic data for the general Polish population were obtained from the Statistic Poland [29]. Based on that data, the incidence and prevalence rates were estimated using the number of Takayasu's arteritis patients and corresponding census data. The study was conducted in accordance with generally applicable law.

TA is a primary vasculitis that causes stenosis or occlusion, rarely aneurysm and distal ischemia [30]. This type of arteritis may require treatment and advanced diagnostic procedures that can be performed in inpatient settings. Analysis of hospitalizations of TA patients from the National Register in multi-year time of observation may be a good way to estimate the epidemiology of this rare, but still life-threatening disease which may negatively affects pregnancy outcomes.

Statistical analysis. All statistical analyses were performed using the licensed version of Statistica Software [31] and WINPEPI programmes [32]. The results of descriptive analyses were expressed as means, medians and ranges for continuous variables, and counts and percentages for categorical data. 95\% CIs were calculated assuming Poisson distributions of the observed cases. The incidence rate was calculated using the number of disease cases divided as the population figure. Linear regression was used for trend analysis. Nonparametric tests were used as appropriate when normality assumptions were not met. A two-sided $P$ value less than 0.05 was considered to be statistically significant.

\section{RESULTS}

Data included 660 hospitalization records. The final study sample consisted of 177 patients with first-time hospitalization for TA between 2011-2015. The number of first-time hospitalization per year varied from 47 in 2011 to 31 in 2015. The mean age was 45.4 years (95\% CI: 42.9-47.8; SD 16.8; range 4-81 years), median 47 . Among the TA patients, $37 \%$ were aged $\leq 40$ years and $59 \%$ were aged $\leq 50$ years at diagnosis of TA. The mean age of female patients was 47.2 years (95\%CI: 44.6-49.7; SD 16.0; range $4-81$ years) and the mean age of male patients was 33.0 years $(95 \% \mathrm{CI}$ : 25.7-40.4; SD 16.9; range $14-66$ years). The mean age of male patients was significantly lower compared to female patients $(\mathrm{p}<0.001)$. Based on hospitalization records and census data, the annual incidence of TA was estimated to be 0.92 per million (95\%CI: 0.677-1.161). Five-year TA prevalence was estimated to be 4,6 per million. TA was more frequently observed among women than men $(87 \%$ vs $13 \%$; $P<0.001)$. The number of newly-diagnosed TA cases in Poland by gender per year across the study period is presented in Figure 1. Age distribution of first-time hospitalized patients with Takayasu's arteritis in Poland was presented in Figure 2. During the study period, four of the patients (one male and three females) died during hospitalization. Incidence rate of TA did not vary significantly between more urban and more rural regions. 


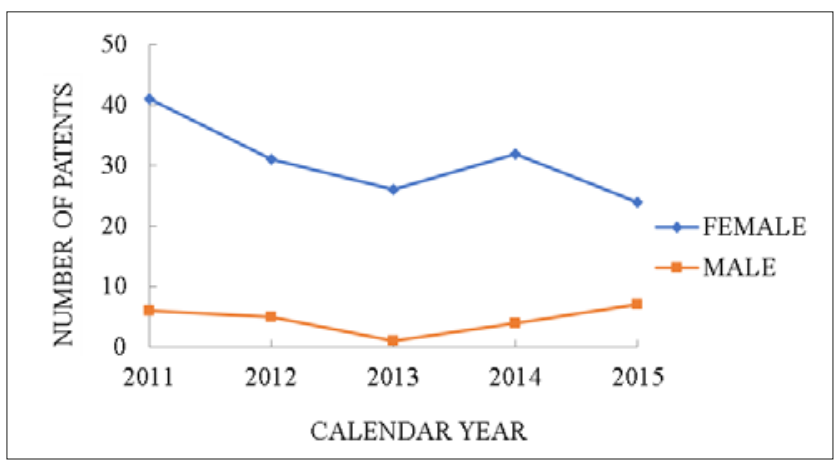

Figure 1. Incidence of TA by gender, 2011-2015

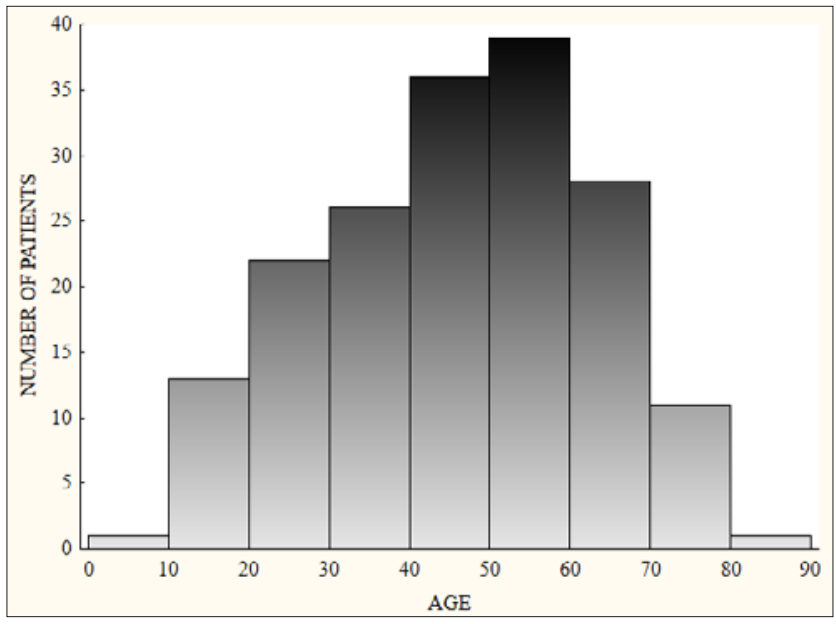

Figure 2. Age distribution of TA patients, 2011-2015

\section{DISCUSSION}

Although epidemiological data on the incidence and prevalence of TA have been reported in several European countries, to the best of our knowledge this analysis is the first to investigate the epidemiology of this chronic disease in Poland. Diagnosis of TA often requires advanced diagnostic or therapeutic procedures, and an analysis of hospitalization data can provide accurate estimates of the epidemiology of this disease. Based on the data obtained from a national inpatient discharge database, the average annual incidence of TA in Poland was estimated at 0.92 per million per year, which is comparable to those reported in other European countries [15-21]. Comparing the incidence, large diversity on a global scale were not observed, which may suggest the small impact of environmental factors on the TA incidence in Poland.

Five-year TA prevalence was estimated to be 4,6 per million. Of course, the prevalence of TA in Poland is underestimated by the relatively short period of the study. A longer period of observation allows to better estimate the prevalence of this disease in Poland. The incidence rate of Takayasu's arteritis did not vary significantly between more urban and more rural regions in this study.

TA predominantly affects females and this study also the reported female to male ratio at 6.7:1. Other studies from European countries reported slight differences in TA female to male ratio. Recent studies northeren Europe [19] reported a quite high female to male ratio of 9:1. Data from the French Takayasu network reported that $86.8 \%$ were women [33]. In an Italian study among 104 patients, 91 were women (87.5\%) and 13 men (12.5\%) [1]. A recent Japanese study reported a female to male ratio of $5: 1$ [34]. In a recent study from the Republic of Korea, the female to male ratio was reported to be 6.9:1 [35]. In other studies from China, the female to male ratio was 3.8 to 1 [36] or $79.1 \%$ of the patients were women [37].

Data from other European countries reported various age in TA patients. In this study, the mean age was 45.4 and median 47 years, $37 \%$ were aged $\leq 40$ years and $59 \%$ were aged $\leq 50$ years, the mean age at diagnosis was significantly lower among male patients compared to females. From the other side, a recent Japanese study reported the mean age at diagnosis was significantly lower among male patients, compared to females -34 versus 43.5 years, and the proportion of female patients aged $\leq 40$ years at onset was less than half of the patients [34]. Data from the French Takayasu network reported that the median age at TA diagnosis was 36 years [33]; in Greece, the median age at TA onset was 31 years [38]; in southern Sweden the median age at TA diagnosis was 23 years [17] and in eastern Denmark the median patient age at the time of the TA diagnosis was 36.3 years [18].

In a few European countries median age was higher than that reported from Poland in the current study., e.g. in the UK, the median age was 51 years [16]. In a recent study, northern Europeans had a mean age of 36.3 years at diagnosis [19]. In an Italian study, the mean age at disease onset (determined by the occurrence of the earliest specific symptom or a finding attributable to the disease) was 29.4 years in men and 29.1 years in women, a difference that was not statistically significant [1]. It is worth mentioning that in studies from China the reported the mean age at onset was $28.9 \pm 12.0$ years [36], and in another study the median age at onset of the disease was 23 years old [37]. In a retrospective, one-centre study from Poland the mean age at disease onset was 26 years, but it was highlighted that the mean diagnostic delay was 19 months [28].

These variations among the presented studies may derive from geographical and genetic differences between the populations, but also may be due to methodological differences [39]. The results of the current study suggest the participation of many factors that may increase the risk of disease. The genetic factors and gender may probably play a more important role in the development of TA in Poland than territorial factors.

In this study we observed 4 deaths during five years observation. In a US cohort of 126 patients, the overall survival was $97 \%$ at 10 years and $86 \%$ at 15 years [40]. In a retrospective multi-centre study from the French Takayasu network after a median follow-up of 6.1 years, death was observed in 5\% [33]. Among the Chinese, the median survival time was 102.5 months [41]. Mortality rate estimation was reported to be $2.8 \%$ (2000-2010) among the Japanese [3]. In other study from Japan, the overall survival rates for patients with TA were $97.7 \%, 97.7 \%$ and $95.3 \%$ at one, five and 10 years [42]. In a study from South Korea, survival rates were $92.9 \%$ at the fifth year and $87.2 \%$ at the tenth year [43].

Strengths and limitations. The authors believe that the current study has major strengths. Since it was performed in a large population of Poland, it produced a large, unselected TA cohort. However, the presented study also has some limitations, one of which is that it was based on a retrospective review, and relied on the discharge records from inpatient hospitalizations. This excludes patients who were seen only as outpatients or were in a stable period of this disease and had not needed hospitalization for more than five years. The first 
appearance of diagnosis of Takayasu's arteritis in the inpatient discharge database does not necessarily have to be the date of first diagnosis. This may lead to overestimation of the count of incident cases. Nevertheless, the 5-year period time of observation in this study may minimize the overestimation.

\section{CONCLUSIONS}

Takayasu's arteritis incidence in Poland is lower or comparable to that in other European countries. Incidence rates of TA did not vary significantly between more urban and more rural regions. The disease was observed more often in females than males. The occurrence of Takayasu's arteritis may be related to many factors, but genetic and personal factors seem to be more relevant than those connected with the environment. The number of people suffering from Takayasu's arteritis may be underestimated, but a better described epidemiology may be achieved using data from national registers in a longer follow-up.

\section{REFERENCES}

1. Vanoli M, Daina E, Salvarani C, Sabbadini MG, Rossi C, Bacchiani G, et al. Takayasu's arteritis: A study of 104 Italian patients. Arthritis Rheum. 2005; 53(1): 100-107.

2. Johnston SL, Lock RJ, Gompels MM. Takayasu arteritis: a review. J Clin Pathol. 2002; 55(7): 481-486.

3. Ohigashi H, Haraguchi G, Konishi M, Tezuka D, Kamiishi T, Ishihara $\mathrm{T}$, et al. Improved prognosis of Takayasu arteritis over the past decade - comprehensive analysis of 106 patients. Circ J Off J Jpn Circ Soc. 2012; 76(4): 1004-1011.

4. Gudbrandsson B, Wallenius M, Garen T, Henriksen T, Molberg O, Paln O. Takayasu Arteritis and Pregnancy: A Population-Based Study on Outcomes and Mother/Child-Related Concerns. Arthritis Care Res. 2017; 69(9): 1384-1390.

5. Comarmond C, Mirault T, Biard L, Nizard J, Lambert M, Wechsler B, et al. Takayasu Arteritis and Pregnancy. Arthritis Rheumatol Hoboken NJ. 2015; 67(12): 3262-3269.

6. Kobayashi Y, Numano F. Takayasu arteritis. Intern Med. 2002; 41(1): 44-46.

7. Sahin Z, Bicakcigil M, Aksu K, Kamali S, Akar S, Onen F, et al. Takayasu's arteritis is associated with HLA-B ${ }^{\star} 52$, but not with HLA-B ${ }^{\star} 51$, in Turkey. Arthritis Res Ther. 2012; 14(1): R27.

8. Terao C, Yoshifuji H, Mimori T. Recent advances in Takayasu arteritis. Int J Rheum Dis. 2014; 17(3): 238-247.

9. Koide K. Takayasu arteritis in Japan. Heart Vessels Suppl. 1992; 7: 48-54.

10. Saritas F, Donmez S, Direskeneli H, Pamuk ON. The epidemiology of Takayasu arteritis: a hospital-based study from northwestern part of Turkey. Rheumatol Int. 2016; 36(7): 911-916.

11. Birlik M, Kücükyavas Y, Aksu K, Solmaz D, Can G, Taylan A, et al. Epidemiology of Takayasu's arteritis in Turkey. Clin Exp Rheumatol. 2016; 34 (3 Suppl 97): 33-39.

12. Nesher G, Ben-Chetrit E, Mazal B, Breuer GS. The Incidence of Primary Systemic Vasculitis in Jerusalem: A 20-year Hospital-based Retrospective Study. J Rheumatol. 2016; 43(6): 1072-1077.

13. Makin K, Isbel M, Nossent J. Frequency, presentation, and outcome of Takayasu arteritis in Western Australia. Mod Rheumatol. 2017; 27(6): 1019-1023.

14. Mustafa KN. Takayasu's arteritis in Arabs. Clin Rheumatol. 2014; 33(12): 1777-1783.

15. Reinhold-Keller E, Herlyn K, Wagner-Bastmeyer R, Gross WL. Stable incidence of primary systemic vasculitides over five years: results from the German vasculitis register. Arthritis Rheum. 2005; 53(1): 93-99.

16. Watts R, Al-Taiar A, Mooney J, Scott D, Macgregor A. The epidemiology of Takayasu arteritis in the UK. Rheumatol Oxf Engl. 2009; 48(8): 1008-1011.

17. Mohammad AJ, Mandl T. Takayasu arteritis in southern Sweden. J Rheumatol. 2015; 42(5): 853-858.

18. Dreyer L, Faurschou M, Baslund B. A population-based study of Takayasu's arteritis in eastern Denmark. Clin Exp Rheumatol. 2011; 29 (1 Suppl 64): 40-42.
19. Gudbrandsson B, Molberg Ø, Garen T, Palm Ø. Prevalence, Incidence, and Disease Characteristics of Takayasu Arteritis by Ethnic Background: Data From a Large, Population-Based Cohort Resident in Southern Norway. Arthritis Care Res. 2017; 69(2): 278-285.

20. Romero-Gómez C, Aguilar-García JA, García-de-Lucas MD, CotosCanca R, Olalla-Sierra J, García-Alegría JJ, et al. Epidemiological study of primary systemic vasculitides among adults in southern Spain and review of the main epidemiological studies. Clin Exp Rheumatol. 2015; 33(2 Suppl 89): 11-18.

21. Dadoniene J, Kirdaite G, Mackiewicz Z, Rimkevicius A, Haugeberg G, et al. Incidence of primary systemic vasculitides in Vilnius: a university hospital population based study. Ann Rheum Dis. 2005; 64(2): 335-336.

22. Kalawski R, Chęciński P, Synowiec T, Greberski K, Bugajski P, Jarząbek $\mathrm{R}$. Takayasu's arteriopathy with associated occlusion of right coronary artery, brachiocephalic trunk and left subclavian artery and aortic regurgitation. Cardiovascular approach leading to a successful outcome - a case presentation. Kardiol Pol. 2010;68(10):1189-1191.

23. Korzon M, Bukowska W, Kotłowska-Kmieć A, Kamińska B. [Takayasu’s disease in a 14 years old girl] Polish. Med Wieku Rozwoj. 2004; 8(1): $125-132$.

24. Wasilewska M, Adamiec R, Hendrich B, Gosk Bierska I. Coexistence of Takayasu's arteritis and ulcerative colitis. Vasa. 2015; 44(1): 71-74.

25. Sadurska E, Jawniak R, Majewski M, Czekajska-Chehab E. Takayasu arteritis as a cause of arterial hypertension. Case report and literature review. Eur J Pediatr. 2012; 171(5): 863-869.

26. Andrzejewska K, Starba A, Misterska-Skóra M, Wiland P, Guziński M. Palpable mass of the neck in the course of Takayasu arteritis. Reumatologia. 2017; 55(1): 48-52.

27. Peruga JZ, Figiel Ł, Kasprzak JD. Acute coronary syndrome as the first manifestation of Takayasu's disease. Kardiol Pol. 2017; 75(3): 281.

28. Czuszyńska Z, Zdrojewski Z. [Clinical manifestations of Takayasu's arteritis seen at the University Medical Center in Gdańsk] Polish. Ann Acad Med Stetin. 2010; 56 (Suppl 1): 95-98.

29. Statistics Poland. http://stat.gov.pl. (access: 13 Oct 2016).

30. Soto ME, Espinola-Zavaleta N, Ramirez-Quito O, Reyes PA Echocardiographic follow-up of patients with Takayasu's arteritis: five-year survival. Echocardiography. 2006; 23(5): 353-360.

31. Dell Inc. (2016) Dell Statistica (data analysis software system), version 13. software.dell.com.

32. Abramson JH. WINPEPI updated: computer programs for epidemiologists, and their teaching potential. Epidemiol Perspect Innov. 2011; 8: 1 .

33. Comarmond C, Biard L, Lambert M, Mekinian A, Ferfar Y, Kahn J-E, et al. Long-Term Outcomes and Prognostic Factors of Complications in Takayasu Arteritis: A Multicenter Study of 318 Patients. Circulation. 2017; 136(12): 1114-1122.

34. Watanabe Y, Miyata T, Tanemoto K. Current Clinical Features of New Patients With Takayasu Arteritis Observed From Cross-Country Research in Japan: Age and Sex Specificity. Circulation. 2015; 132(18): 1701-1709.

35. Lim AY, Lee GY, Jang SY, Gwag HB, Choi SH, Jeon E-S, et al. Gender differences in clinical and angiographic findings of patients with Takayasu arteritis. Clin Exp Rheumatol. 2015; 33 (2 Suppl 89): 132-137.

36. Yang L, Zhang H, Jiang X, Zou Y, Qin F, Song L, et al. Clinical Manifestations and Longterm Outcome for Patients with Takayasu Arteritis in China. J Rheumatol. 2014; 41(12): 2439-2446.

37. Li J, Sun F, Chen Z, Yang Y, Zhao J, Li M, et al. The clinical characteristics of Chinese Takayasu's arteritis patients: a retrospective study of 411 patients over 24 years. Arthritis Res Ther. 2017; 19(1): 107.

38. Karageorgaki ZT, Bertsias GK, Mavragani CP, Kritikos HD, Spyropoulou-Vlachou M, Drosos AA, et al. Takayasu arteritis: epidemiological, clinical, and immunogenetic features in Greece. Clin Exp Rheumatol. 2009; 27 (1 Suppl 52): 33-39.

39. Onen F, Akkoc N. Epidemiology of Takayasu arteritis. Presse Med. 2017; 46(7-8 Pt 2): 197-203. Epub 2017 Jul 26.

40. Schmidt J, Kermani TA, Bacani AK, Crowson CS, Cooper LT, Matteson EL, et al. Diagnostic features, treatment, and outcomes of Takayasu arteritis in a US cohort of 126 patients. Mayo Clin Proc. 2013; 88(8): $822-830$.

41. Li J, Zhu M, Li M, Zheng W, Zhao J, Tian X, et al. Cause of death in Chinese Takayasu arteritis patients. Medicine (Baltimore). 2016; 95(27): 4069.

42. Yoshida M, Watanabe R, Ishii T, Machiyama T, Akita K, Fujita Y, et al. Retrospective analysis of 95 patients with large vessel vasculitis: a single center experience. Int J Rheum Dis. 2016; 19(1): 87-94.

43. Park M-C, Lee S-W, Park Y-B, Chung NS, Lee S-K. Clinical characteristics and outcomes of Takayasu's arteritis: analysis of 108 patients using standardized criteria for diagnosis, activity assessment, and angiographic classification. Scand J Rheumatol. 2005; 34(4): 284292. 